\section{Women are often overlooked in ocean governance}

The authors offer a short review of gendered issues in ocean governance, here defined as "the political, social, economic, and administrative systems and related formal and informal institutional arrangements involved in the management of natural resources."

In a positive finding, the authors note that female scientists comprise $38 \%$ of ocean researchers worldwide: $10 \%$ more than in the research field overall. However, women's contributions to sustainable management and conservation are often overlooked. Fisheries statistics typically do not keep track of the work women contribute, despite the growing contributions of women to the sector especially in permitting and compliance. The authors note several studies have found women practice more environmentally- and economicallysustainable behaviors than men. Women have also been shown to follow conservation rules more so than men. However, from research in the field of gender studies, the perspective of 'women saving the planet' has been noted to be too simplistic, since roles between men and women are renegotiated under changing conditions.

Gendered issues are even studied differently depending on where the analysis is taking place. These issues are typically studied only in developing countries: industrialized, Western countries generally do not examine issues like how climate change will uniquely affect women. Women's contributions to ocean management are also typically ignored in the west, where participatory environmental management is often undervalued and underpowered due to the gendered framing of this type of management.

Moving forward in ocean governance, barriers to equal contributions from all genders should be identified and removed. The authors note: "Women and gender studies should not be confined in a separated category from ocean governance. By separating and labelling, we confine women's contribution from the real decision making arenas. It is time to remove barriers for women to access to government and governance arenas for the sake of ocean sustainability."
This is a summary of: Un-gendering the ocean: Why women matter in ocean governance for sustainability

Accessible at: https://marxiv.org/sju6d/

Authors: Elena Gissi, Michelle Portman, and AnnaKatharina Hornidge

Added to MarXiv: September 2018

Published: Marine Policy, 2018

Suggested Citation: Women are often overlooked in ocean governance. OCTO (2018). DOI: 10.31230/osf. io/4yqgk

See more MarXiv summaries at https://www.marxivinfo.org/ summaries

Join the MarXiv Summaries monthly newsletter at https:// oct.to/marxivsum

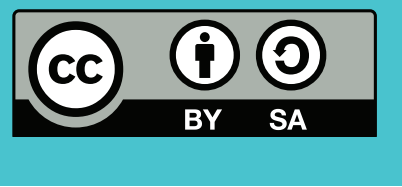

MarXiv is an ОСТO Initiative
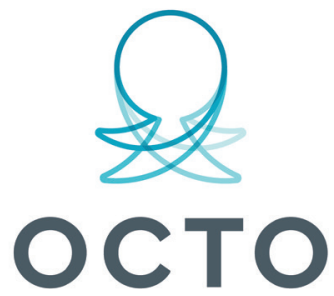

OPEN COMMUNICATIONS FOR THE OCEAN 